\title{
Effects of xanthan gum on the rheological properties of soy protein dispersion
}

\author{
Chonghao $\mathrm{Bi}^{1}$, Fei $\mathrm{Gao}^{2}$, Yingdan $\mathrm{Zhu}^{3}$, Fang $\mathrm{Ji}^{4}$, Yulai Zhang ${ }^{1}$, Dong $\mathrm{Li}^{3}$, Zhigang Huang ${ }^{1 *}$ \\ (1. School of Materials Science and Mechanical Engineering, Beijing Technology and Business University, Beijing 100048, China; \\ 2. Biomass and Bioresource Utilization Laboratory, College of Engineering, China Agricultural University, Beijing 100083, China; \\ 3. Beijing Advanced Innovation Center for Food Nutrition and Human Health, College of Engineering, National Energy R\&D Center for \\ Non-food Biomass, China Agricultural University, Beijing 100083, China; \\ 4. Chinese Academy of Agricultural Engineering, Beijing 100125, China)
}

\begin{abstract}
This study focused on the effects of addition of xanthan gum (XG) on the rheological properties of soy protein isolate (SPI) solution. Three types of tests (steady shear test, strain sweep test, and frequency sweep test) were performed to figure out the influences of shear rate on the viscosity of the SPI-XG hybrid system, the effects of strain variable on the storage modulus of the hybrid system, and the effects of frequency on both the storage modulus and the loss modulus of the hybrid system, respectively. SPI-XG hybrid system showed more obvious shear-thinning properties compared to pure SPI and pure XG solution. Meanwhile, it was found that the critical point of hybrid system was highly related to the XG concentration. $\mathrm{XG}$ can postpone the critical point strain amplitude to a higher value, and the addition of XG can enhance the strain resistance of hybrid system. The concentration of XG influenced the viscoelastic frequency dependence of the hybrid system significantly and complicatedly. After the addition of $\mathrm{XG}$, the correlation between $G^{\prime}$ and frequency changed from negative to positive.
\end{abstract}

Keywords: rheological property, soy protein isolate (SPI), xanthan gum (XG), temperature, frequency independence DOI: $10.25165 /$ j.ijabe.20181102.3253

Citation: Bi C H, Gao F, Zhu Y D, Ji F, Zhang Y L, Li D, et al. Effects of xanthan gum on the rheological properties of soy protein dispersion. Int J Agric \& Biol Eng, 2018; 11(2): 208-213.

\section{Introduction}

Proteins are large bio-molecules, consisting of one or more long chains of amino acid-residues. Proteins perform a vast array of functions within organisms, including catalysing metabolic reactions, DNA replication, responding to stimuli, and transporting molecules from one location to another ${ }^{[1]}$. Participating in all organisms' essential reaction, protein is an important component of the human body's cells. In general, the proportion of protein in the total dry mass of the human body is approximately $18 \%$, which is an element close to human life ${ }^{[2]}$. Soy protein isolate (SPI) is a kind of protein food additive that can be obtained from low-temperature desolventizing soybean meal as raw materials ${ }^{[3]}$. SPI has many functional properties of emulsifying, foaming, gelation and film forming ${ }^{[4]}$. Moreover, SPI is also abundant in nutrients and has the features of reducing serum cholesterol and preventing cardiopathy and cerebrovascular disease. The demand

Received date: 2017-02-09 Accepted date: 2017-12-28

Biographies: Chonghao $\mathbf{B i}, \mathrm{PhD}$, research interests: material property characteristics, non-linear rheological analysis and fractal analysis, Email: bichonghao@btbu.edu.cn; Fei Gao, PhD, research interests: rheology and spectroscopy of biomaterial, Email: Sophia_gophi@163.com; Yingdan Zhu, $\mathrm{PhD}$, research interests: material property characteristics, Email: zhuyingdan@ cau.edu.cn; Fang Ji, PhD, research interests: biomass energy, Email: ji_fang1984@163.com; Yulai Zhang, Master, research interests: non-linear rheological analysis, Email: 804968645@qq.com; Dong Li, Professor, research interests: interaction between protein and polysaccharide, Email: dongli@, cau.edu.cn.

*Corresponding author: Zhigang Huang, Professor, research interests: functional properties of food ingredients and food manufacturing machinery. Gengyun Building No.11 Fu Cheng Road Haidian District, Beijing 100048, China. Tel/Fax: +86-10-68985249, Email: huangzg@btbu.edu.cn. of SPI is continuously growing because of its nutritional and functional properties ${ }^{[5,6]}$. Therefore, SPI, as a kind of functional ingredient, has been developing extensively in food industry. In addition, some specific properties of SPI can be modified with the appropriate addition of other materials.

Polysaccharide is composed of multiple monosaccharide molecules, which is a kind of carbohydrate. They range in structure from linear to highly branched ${ }^{[7]}$. Examples include storage polysaccharides such as starch and glycogen, and structural polysaccharides such as cellulose and chitin. Gum, such as pectin and gelatin, is a kind of polysaccharide, which is extensively applied in food industry ${ }^{[8]}$. Xanthan Gum (XG), the study subject in this article, is single spore microbe polysaccharide, which is able to dissolve not only in cold water but also in hot water ${ }^{[9-11]}$. The solution of $\mathrm{XG}$ is neutral. $\mathrm{XG}$ is a complex polysaccharide fermented using Xanthomonas campestris, which is mainly produced by corn starch as substrate ${ }^{[12,13]}$. XG can act as emulsifier, stabilizer and gel thickener in the food industry due to the functional properties, such as emulsifying property, thermal stability, thickening property ${ }^{[14,15]}$. Compared with the common edible gums of pectin and gelatin, the XG has more stable property and is more predominant in food processing ${ }^{[16,17]}$.

Protein and polysaccharide play an important role in manufactured foods due to their unique functional and textural properties. when protein and polysaccharide are hydride, it is expected that their behaviors are affected by each other ${ }^{[18]}$. It was found that the charged polysaccharides readily interact with other macromolecules such as lipid and protein ${ }^{[19]}$. The bio-macromolecules interact with each other through weak interactions such as electrostatic forces, Van der Waal forces, hydrogen bonds, and hydrophobic systems ${ }^{[20]}$. When protein 
mixed with polysaccharide, a hybrid system can be gained only in some particular circumstances, such as given temperature, proper $\mathrm{pH}$, and appropriate ionic strength. Protein-polysaccharide hybrid system has more powerful functional properties compared to pure protein or pure polysaccharide because of the interaction between protein and polysaccharide.

In food industry, the interaction of protein and polysaccharide always determined the texture and acceptability of product. For example, polysaccharide is always applied into dairy products as stabilizer and gel thickener to improve the rheological property of emulsion. It forms reticular structure in the space that can prevent delamination caused by phase separation and the gravity. Protein molecule is beneficial to form the emulsion of good stability through the action of static electricity. The interaction of protein and polysaccharide is widely used in increasing the shelf life of milk and improving the products' quality ${ }^{[21]}$. Most proteins in food can occur adsorption with anionic polysaccharide by electrostatic and form a new complex with more excellent characteristics. In this way, the rheological property and adsorption behavior of protein will be improved and the stability of the solution will also be developed. The process that polysaccharide makes protein remain stable is a completed progress. In some circumstance, protein can interact with polysaccharide through static electricity force, hydrophobic force and hydrogen bond. Only in some specific concentration and polymer ratio, a kind of highly homogeneous mixture can be obtained. According to the report, the interaction of protein and polysaccharide has obvious effects on the stability of emulsion.

The rheological property is a type of quantitative relationships between stress and strain on the object suffered from external forces, which is related to the nature and internal structures of object. As a result, it becomes especially important to study the rheological properties of protein-polysaccharide hybrid system. The rheological property study can provide abundant useful information, such as the interaction between food components, the selection standard of different additives, and the processing problems in many aspects such as transportation ${ }^{[22]}$. Usually, the rheological properties of protein-polysaccharide hybrid system are not simply an addition of parameters of two components.

This article mainly studies on the influence of the addition of $\mathrm{XG}$ on the rheological properties of soy protein solution. The formation of hybrid solution of SPI and XG is greatly affected by the temperature and the chemical factors, such as ionic strength, $\mathrm{pH}$ of aqueous phase, and physical factors (high shear). Through steady shear test, strain sweep test and frequency sweep test, the article is devoted to study on the effect of shear rate on the viscosity $(\eta)$ of the SPI-XG hybrid system, the effect of strain variable on the storage modulus $\left(G^{\prime}\right)$ of the SPI-XG hybrid system, and the effect of frequency on both the storage modulus $\left(G^{\prime}\right)$ and the loss modulus $\left(G^{\prime \prime}\right)$ of the SPI-XG hybrid system, respectively.

\section{Materials and methods}

\subsection{Materials}

Commercial SPI (S30914, BR grade, $\mathrm{pH}=7.0 \pm 0.5$, protein content $\geq 90.0 \%$, moisture content $\leq 7.0 \%$ ) was obtained from Shanghai Yuanye Bio-Technology Co. Ltd. (Shanghai, China). XG (G810381, USP grade) was obtained from Shanghai Macklin Biochemical Co. Ltd. (Shanghai, China). The above materials were used in experiment without any processing.

\subsection{Sample preparation}

Six grams SPI powder and $0.25 \mathrm{~g} \mathrm{XG}$ powder were completely dissolved in $100 \mathrm{~mL}$ deionized water by magnetic stirring at $600 \mathrm{r} / \mathrm{min}$ for $20 \mathrm{~min}$, in which the concentration of SPI dispersion liquid and XG solution were $6 \%$ and $0.25 \%$. After that, $9 \mathrm{~g}$ SPI powder was dissolved in $100 \mathrm{~mL}$ deionized water using the magnetic stirrer $(600 \mathrm{r} / \mathrm{min})$ for $20 \mathrm{~min}$. The third stage was to dissolve $0.075 \mathrm{~g}, 0.225 \mathrm{~g}$ and $0.375 \mathrm{~g} \mathrm{XG}$ powder in $50 \mathrm{~mL}$ deionized water respectively, and the solutions were stirred at $600 \mathrm{r} / \mathrm{min}$ for $20 \mathrm{~min}$. Two kinds of solutions (which are formed in the second and third stage) were mixed and continue stirred for 20 min to completely mix. Then, three kinds of solution have been prepared: $6 \%$ SPI- $0.05 \%$ XG hybrid system; $6 \%$ SPI$0.15 \%$ XG hybrid system; $6 \%$ SPI- $0.25 \%$ XG hybrid system. All the samples were performed at room temperature $\left(25^{\circ} \mathrm{C}\right)$ and stored in the refrigerator at $4^{\circ} \mathrm{C}$ overnight for further rheological test.

Before testing, the overnight samples needed to be stirred for 5 min on magnetic stirrer to ensure the homogeneity of the samples.

\subsection{Methods}

\subsubsection{Rheological test}

The tests of rheological properties were all conducted on AR2000ex rheometer (TA Instruments Company, USA) and the temperature control was in charged by Peltier system. In the experiment, the aluminum parallel plate geometry ( $40 \mathrm{~mm}$ diameter) was selected, and the gap between the geometry and Peltier plate was $1000 \mu \mathrm{m}$. Before all the tests, samples need to be equilibrated on the rheometer for $2 \mathrm{~min}$ to eliminate the impact of sample loading on the final result.

The characterization of rheological properties consisted of three tests: steady shear test, strain sweep test, and frequency sweep test. Each test was performed in a continuous temperature changing process.

\subsubsection{Steady shear test}

The temperature was set at $25^{\circ} \mathrm{C}$, and the shear rate needed to be controlled in the range of 1-100 $\mathrm{s}^{-1}$. In food industry, some common operating frequencies are as follows: 1-100 $\mathrm{s}^{-1}$ for extrusion; 1-1000 $\mathrm{s}^{-1}$ for pipe flow; 10-1000 $\mathrm{s}^{-1}$ for stirring ${ }^{[23]}$. The controlled range of shear rate in this test was accordance with the above shear rate.

Temperature-changing test: in the test of influence of temperature on the rheological properties of the hybrid system, temperatures of the test were controlled in three gradients at $25^{\circ} \mathrm{C}$, $45^{\circ} \mathrm{C}$ and $65^{\circ} \mathrm{C}$, and the shear rate is also set in the range of 1 $100 \mathrm{~s}^{-1}$.

\subsubsection{Strain sweep test}

In strain sweep test, the strain amplitude was set in the range of $0.1 \%-10.0 \%$, which was within the vibration strength during food processing and transportation. Temperature was set at $25^{\circ} \mathrm{C}, 45^{\circ} \mathrm{C}$ and $65^{\circ} \mathrm{C}$, respectively. And the oscillatory frequency was $1 \mathrm{~Hz}$. The value of storage modulus $\left(G^{\prime}\right)$ and the loss modulus $\left(G^{\prime \prime}\right)$ were recorded during the strain sweep test every 10 point per decade. Linear Viscoelastic Region (LVR) of each sample in each temperature was determined for the following dynamic rheological test. When the strain amplitude applied in the LVR, the change of strain amplitude do not impact the detected values of $G^{\prime}$ and $G^{\prime \prime}$.

\subsubsection{Frequency sweep test}

Frequency sweep test conducted after strain sweep test, since the oscillatory strain amplitude of this test have to be within the LVR of each sample, which obtained from the strain sweep test. The temperature of experiment was controlled at $25^{\circ} \mathrm{C}$, and the giving frequency was set during $0.1 \mathrm{~Hz}$ to $1 \mathrm{~Hz}$ taking 10 points per logarithmical decades. The setting strain was controlled at 
$0.2 \%$, and both the storage modulus $\left(G^{\prime}\right)$ and the loss modulus $\left(G^{\prime \prime}\right)$ of SPI-XG hybrid system was detected and recorded as a function of frequency.

The frequency dependence of both storage modulus $\left(G^{\prime}\right)$ and loss modulus $\left(G^{\prime \prime}\right)$ of SPI-XG hybrid system could be fitted by the Power Law Model ${ }^{[24]}$ :

$$
\begin{aligned}
G^{\prime} & =K^{\prime} \cdot f^{n^{\prime}} \\
G^{\prime \prime} & =K^{\prime \prime} \cdot f^{n^{\prime \prime}}
\end{aligned}
$$

where, $K^{\prime}$ and $K^{\prime \prime}$ are the power law constant, $\mathrm{Pa} \cdot \mathrm{s}^{\mathrm{n}} / \mathrm{rad}^{\mathrm{n}} ; n^{\prime}$ and $n^{\prime \prime}$ are frequency indexes, which is to reflect the viscoelasticity frequency dependence of samples ${ }^{[25,26]}$.

In order to investigate the effect of temperature on the frequency dependence of the hybrid system, the temperature was controlled in three gradients at $25^{\circ} \mathrm{C}, 45^{\circ} \mathrm{C}$ and $65^{\circ} \mathrm{C}$.

\subsubsection{Statistical analysis}

The experimental data of rheological test can be obtained directly from software supporting with rheometer on computer. All the above experiments were repeated three times, and the average values were shown in tables and figures. Regressions and corresponding equations were processed by SPSS statistical package (SPSS 16.0, IBM Corporation, USA).

\section{Results and discussion}

\subsection{Steady shear test}

The effect of shear rate on the viscosity $(\eta)$ of the SPI-XG hybrid system at $25^{\circ} \mathrm{C}$ is shown in Figure 1. It can be observed from the diagram that within the shear rate range of steady shear test $\left(1-100 \mathrm{~s}^{-1}\right)$, the pure XG sample shows the lowest viscosity, following by the pure SPI samples. With the increase of the concentration of XG, the viscosity of the hybrid system increased. Among all the samples, either the SPI-XG hybrid system or the pure SPI/XG samples, their apparent viscosities increased with the applying shear rate decreasing. This phenomenon indicated that all samples showed obvious shear-thinning properties. The shear-thinning property was related to the molecule re-arrangement of shear direction as a result of molecular structures ${ }^{[27,28]}$. At the beginning, the shear rate was in low velocity zone and the change of molecular structure due to shearing was not obvious. In this shear rate zone, in order to maintain the structure, inner-molecular forces provided a cohesive trend to resist the external force from changing the molecular structure. As a result, the viscosity of SPI-XG hybrid system remained a higher extent in the case of lower shear rate. With the shear rate increasing, the inner-molecular force was not enough to resist the structure change. The original intact molecule was forced to unfold, which greatly reduced the anti-shearing behaviors of molecule, so that apparent viscosity fell with it. Moreover, it can be seen from the diagram, the viscosity of SPI-XG hybrid system (70 Pas, when $\gamma=1 \mathrm{~s}^{-1}$ ) was much higher than that of pure XG (6 Pas, when $\left.\gamma=1 \mathrm{~s}^{-1}\right)$ or pure SPI samples ( 8 Pas, when $\gamma=1 \mathrm{~s}^{-1}$ ), which means SPI and XG have obvious synergistic effect. That may be due to the increasing relative density of protein polymer as a result of adding XG in it.

The effect of temperature on the shear rate curve of the SPI $(6 \%)$-XG $(0.25 \%)$ hybrid system is depicted in Figure 2. According to the graph, within the shear rate range of steady shear test (1-100 $\left.\mathrm{s}^{-1}\right)$, the higher the temperature was, the lower the viscosity of the sample was. That is to say, the increasing temperature can declined the viscosity of the samples. At the same temperature, the apparent viscosity of the sample decreased with the increasing shear rate. Lower temperature led the
SPI-XG hybrid system to more obvious shear-thinning characteristics.

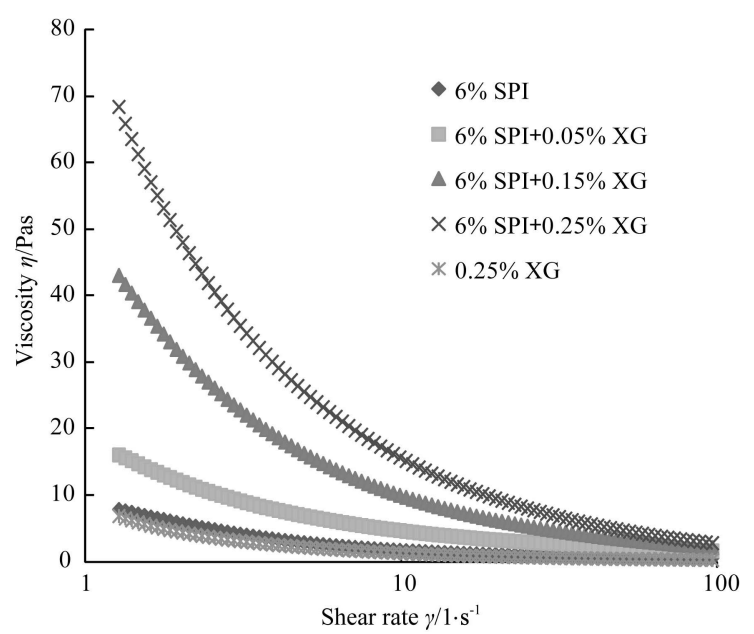

Figure 1 Effects of shear rate on the viscosity $(\eta)$ of the SPI-XG hybrid system $\left(T=25^{\circ} \mathrm{C}\right)$

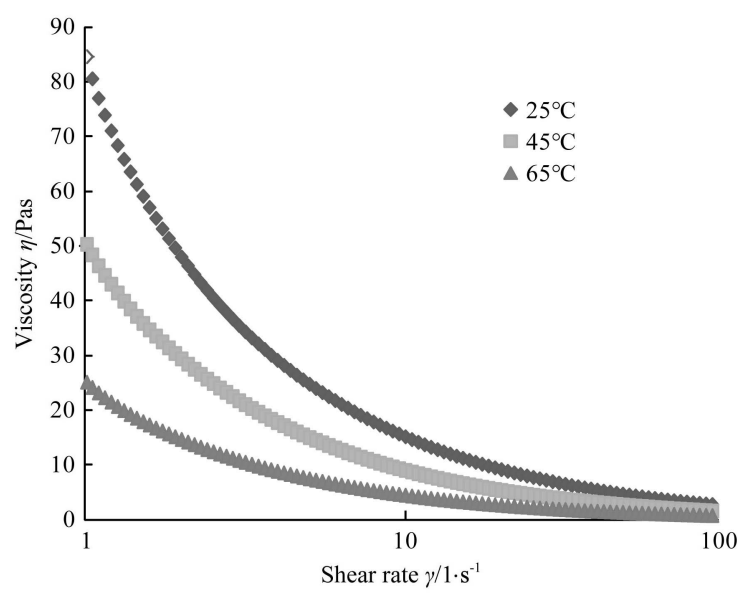

Figure 2 Effects of temperature and shear rate on apparent viscosity $(\eta)$ of the SPI-XG hybrid system

\subsection{Strain sweep test}

The effects of strain amplitude on the storage modulus $\left(G^{\prime}\right)$ of the SPI-XG hybrid system is presented in Figure 3. It can be seen from the diagram, within the strain range of strain sweep test $(0.1 \%-10.0 \%)$, the pure XG $(0.25 \%)$ sample performed the lowest storage modulus (approx. $40 \mathrm{~Pa}$ ), following by the pure SPI $(6 \%)$ sample (approx. $100 \mathrm{~Pa}$ ). With the increase of the concentration of XG, the $G^{\prime}$ value of the hybrid system increased significantly $(6 \% \mathrm{SPI}+0.25 \% \mathrm{XG}$, approx. $700 \mathrm{~Pa})$. At the beginning, the storage modulus curve of the hybrid system showed a platform and began to decline with the strain amplitude increased gradually. We simply defined the data point that $G^{\prime}$ declined to $95 \%$ of $G_{\text {ave }}^{\prime}$ (platform average $G^{\prime}$ value) as the critical point of "LVR",[29,30]. It can be observed from the diagram that with the concentration of XG increasing, the imposed strain amplitude of the LVR critical point rose gradually, which means XG shows the trend to resist the influence of external strain on the elasticity of SPI-XG hybrid system.

Figure 4 shows the effects of temperature on the storage modulus $\left(G^{\prime}\right)$ as a function of strain of the SPI-XG hybrid system. According to the graph, within the strain range of strain sweeping test $(0.1 \%-10.0 \%)$, the storage modulus of the SPI-XG hybrid system decreased significantly with the increase of temperature. The diagram also revealed that the imposed strain on the LVR 
critical point did not change obviously. Hence, the influence of temperature on the elasticity of SPI-XG hybrid system for resistance to the external strain is inconspicuous.

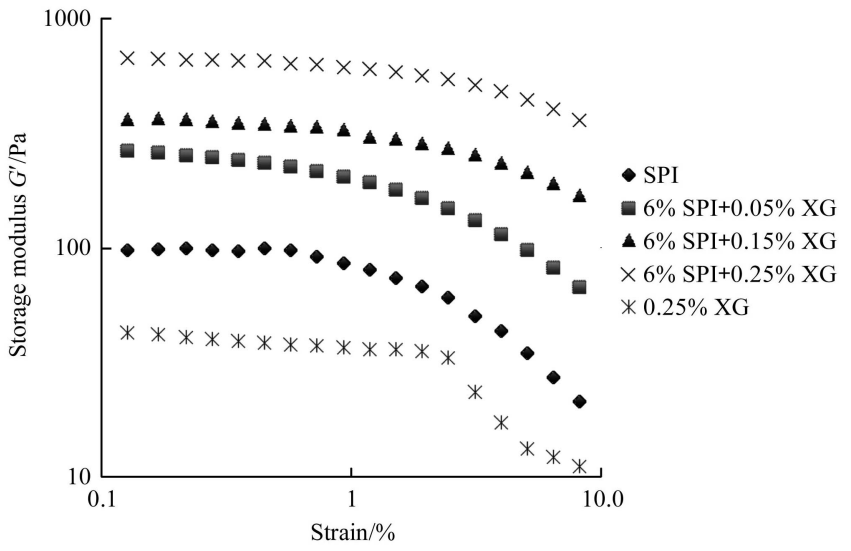

Figure 3 Effects of strain on the storage modulus $\left(G^{\prime}\right)$ of the SPI-XG hybrid system $\left(t=25^{\circ} \mathrm{C}\right)$

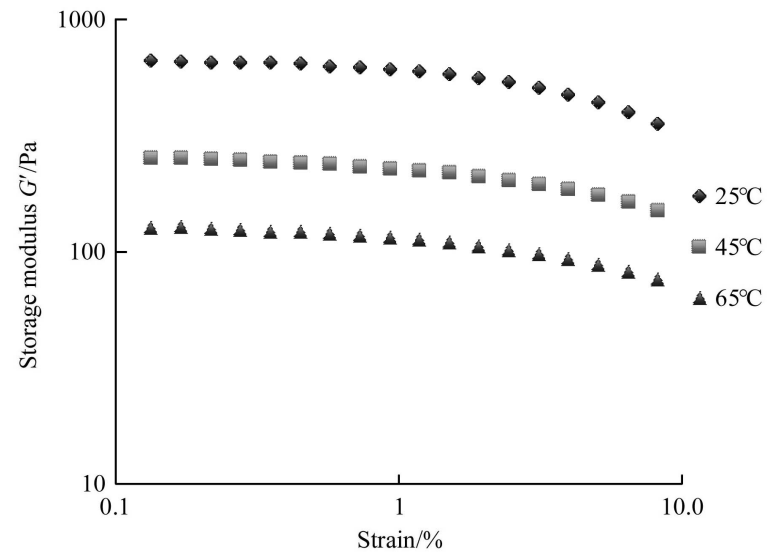

Figure 4 Effects of temperature on storage modulus $\left(G^{\prime}\right)$ of the SPI-XG hybrid system as a function of strain

\subsection{Frequency sweep test}

The effects of frequency on both storage modulus $\left(G^{\prime}\right)$ and loss modulus $\left(G^{\prime \prime}\right)$ of the SPI-XG hybrid system in the case of $0.2 \%$ strain at $25^{\circ} \mathrm{C}$ is shown in Figure 5. Within the applied frequency range $(0.1-1.0 \mathrm{~Hz})$, the value of $G^{\prime}$ and $G^{\prime \prime}$ of all samples increased with the increase of frequency, except for the pure SPI sample. This phenomenon indicated that the addition of XG dominated the frequency dependence performance of SPI-XG hybrid system. At the same frequency, the $G^{\prime}$ and $G^{\prime \prime}$ of pure XG were the lowest, following by that of pure SPI. With the increase of the concentration of XG, the value of $G^{\prime}$ and $G^{\prime \prime}$ of the hybrid system also increased, which means the addition of XG enhances both elasticity characteristic and viscosity characteristic of SPI-XG hybrid system.

The data obtained by frequency sweep test can be regressed by the Power Law Model very well $\left(R^{2}>0.96\right)$. The parameters of the regression are listed in Table 1 . The values of $K^{\prime}$ and $K^{\prime \prime}$ rose sharply because of the increasing concentration of $\mathrm{XG}$, which proved that both the viscosity and elasticity of the SPI-XG hybrid system were strengthen by the addition of XG. The values of $K^{\prime}$ of SPI-XG hybrid system were much higher than the value of $K^{\prime \prime}$ that indicated hybrid system was more elastic. The value of $n^{\prime}$ expressed the frequency dependence extent of the elasticity of samples. The hybrid system showed obvious larger values of $n^{\prime}$ than that of pure XG or pure SPI. This trend indicated that the elastic properties of SPI-XG hybrid system were more frequency dependent than that of pure XG or pure SPI. However, the values of $n^{\prime}$ in this three hybrid systems did not change significantly with the change of concentration of XG. That means concentration of $\mathrm{XG}$ in the hybrid system scarcely has any effect on the frequency dependence of elastic properties. The value of $n^{\prime \prime}$ expressed the frequency dependence extent of the viscosity of samples. The value of $n^{\prime \prime}$ of SPI-XG hybrid system decreased slightly with the addition of XG. That means the addition of XG reduces the frequency dependence of viscous properties, making the SPI-XG hybrid system less sensitive to frequency.
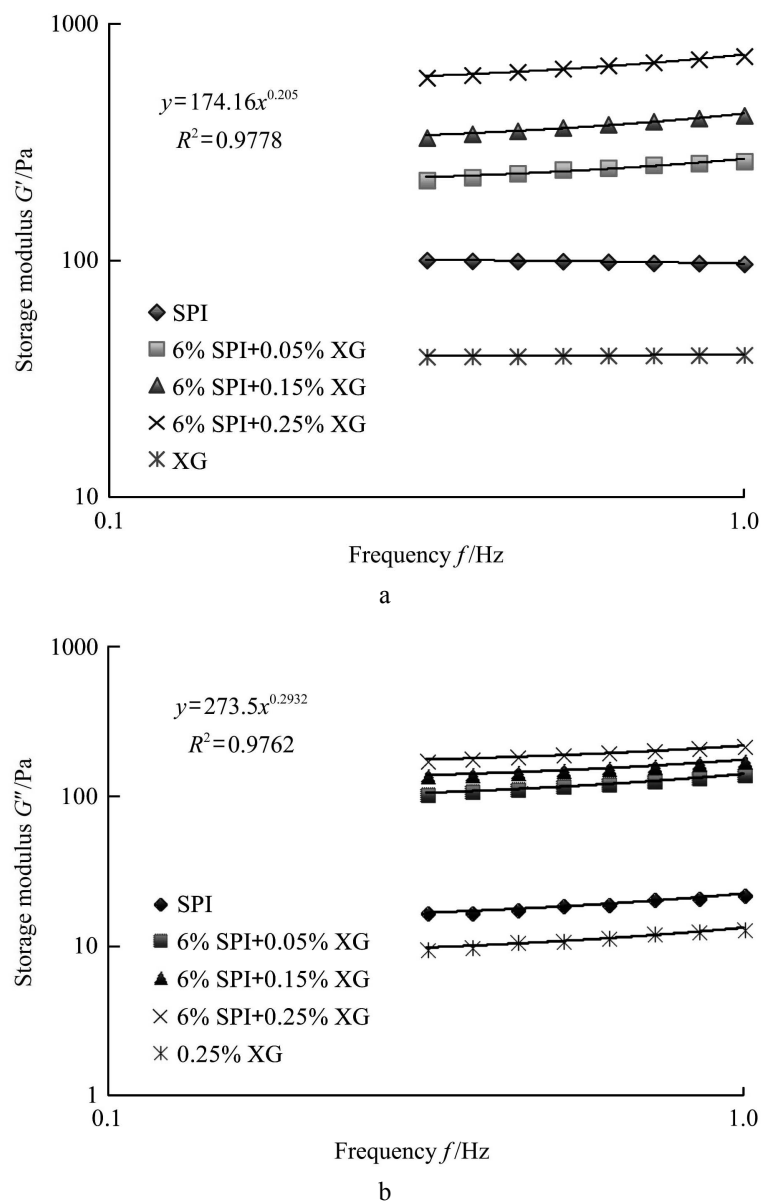

Figure 5 Effects of frequency on the storage modulus $\left(G^{\prime}\right)$ and loss modulus $\left(G^{\prime \prime}\right)$ of the SPI-XG hybrid system $\left(t=25^{\circ} \mathrm{C}, \gamma=0.2 \%\right)$

Table 1 Effects of XG on the parameters of the Power Law Model of SPI-XG hybrid system

\begin{tabular}{cccccccc}
\hline \multirow{2}{*}{ Samples } & \multicolumn{3}{c}{$G^{\prime}=K^{\prime} \cdot f^{n^{\prime}}$} & & \multicolumn{3}{c}{$G^{\prime \prime}=K^{\prime \prime} \cdot f^{n^{\prime \prime}}$} \\
\cline { 2 - 3 } \cline { 7 - 8 } & $K^{\prime}$ & $n^{\prime}$ & $R^{2}$ & & $K^{\prime \prime}$ & $n^{\prime \prime}$ & $R^{2}$ \\
\hline 6\% SPI & 97.239 & -0.3100 & 0.96 & 22.149 & 0.2603 & 0.98 \\
$6 \%$ SPI+0.05\% XG & 266.98 & 0.1626 & 0.98 & 140.08 & 0.2586 & 0.99 \\
$6 \%$ SPI+0.15\% XG & 413.67 & 0.1851 & 0.99 & 174.16 & 0.2050 & 0.99 \\
$6 \%$ SPI+0.25\% XG & 734.65 & 0.1874 & 0.99 & 217.26 & 0.1892 & 0.99 \\
$0.25 \%$ XG & 40.017 & 0.0149 & 0.97 & 12.803 & 0.1927 & 0.99 \\
\hline
\end{tabular}

The effects of temperature on the frequency sweeping spectrums of SPI-XG hybrid system is shown in Figure 6. It can be seen from the diagram, within the frequency range applied (0.1-1.0 Hz), the value of $G^{\prime}$ and $G^{\prime \prime}$ of SPI-XG hybrid system decreased significantly with the temperature increasing, while the trend of the curves did not change a lot.

The parameters of the regression are shown in Table 2. The values of $K^{\prime}$ decreased from $734.65\left(25^{\circ} \mathrm{C}\right)$ to $273.50\left(65^{\circ} \mathrm{C}\right)$ and 
$K^{\prime \prime}$ decreased from $217.26\left(25^{\circ} \mathrm{C}\right)$ to $107.73\left(65^{\circ} \mathrm{C}\right)$, which means the increase of temperature could weaken both the viscosity and elasticity of the SPI-XG hybrid system. The values of $n^{\prime}$ and $n^{\prime \prime}$ increased due to the rising temperature. This trend indicated that increasing temperature strengthened the frequency dependence of both elasticity and viscosity characteristics of SPI-XG hybrid system. In a word, the rheological properties of hybrid system become more sensitive to frequency when the system expose to high temperature.
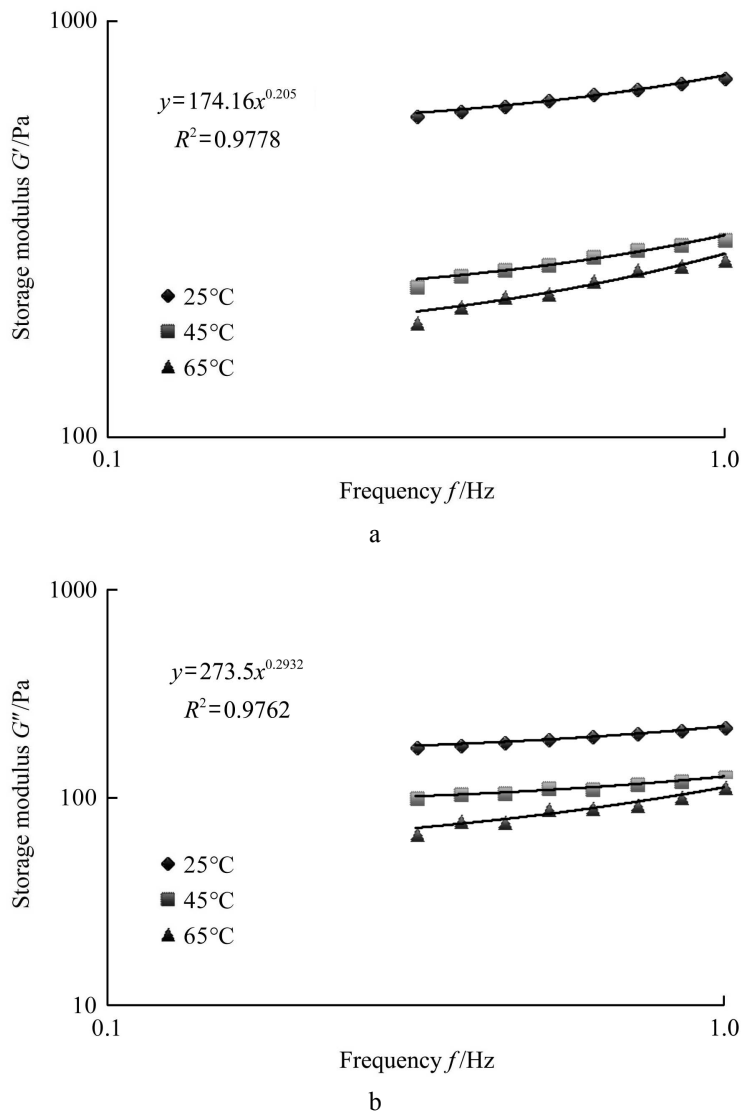

Figure 6 Effects of temperature on the storage modulus $\left(G^{\prime}\right)$ and loss modulus $\left(G^{\prime \prime}\right)$ of the SPI-XG hybrid system $(\gamma=0.2 \%)$

Table 2 Effects of temperature on the parameters of the Power Law Model of SPI-XG hybrid system

\begin{tabular}{cccccccc}
\hline & \multicolumn{3}{c}{$G^{\prime}=K^{\prime} \cdot f^{n^{\prime}}$} & & \multicolumn{3}{c}{$G^{\prime \prime}=K^{\prime \prime} \cdot f^{n^{\prime \prime}}$} \\
\cline { 2 - 4 } \cline { 6 - 8 } Temperature & $K^{\prime}$ & $n^{\prime}$ & $R^{2}$ & & $K^{\prime \prime}$ & $n^{\prime \prime}$ & $R^{2}$ \\
\hline $25^{\circ} \mathrm{C}$ & 734.65 & 0.1874 & 0.99 & 217.26 & 0.1892 & 0.99 \\
$45^{\circ} \mathrm{C}$ & 303.12 & 0.2206 & 0.99 & & 124.37 & 0.1909 & 0.97 \\
$65^{\circ} \mathrm{C}$ & 273.50 & 0.2932 & 0.98 & 107.73 & 0.3997 & 0.95 \\
\hline
\end{tabular}

\section{Conclusions}

This article studied on the effects of $\mathrm{XG}$ addition on the rheological properties of SPI solution. The rheological properties of SPI-XG hybrid system were investigated through the steady shear test, strain sweep test and frequency sweep test.

In steady shear test, SPI-XG hybrid system showed more obvious shear-thinning properties than pure SPI and pure XG solution; the viscosity of the hybrid system presented a sharp increase with the increment of XG concentration. It was proved that there were significant synergistic effects between SPI and XG molecule. That may be due to the increasing relative density of protein polymer as a result of XG addition in the hybrid system.
However, the molecular level interaction between SPI and XG needs to be investigated in further study.

In strain sweep test, the LVR critical point of SPI-XG hybrid system was determined. It was found that the critical point of hybrid system was highly related to the $\mathrm{XG}$ concentration. $\mathrm{XG}$ can postpone the critical point strain amplitude to a higher value. This phenomenon indicated that the addition of $\mathrm{XG}$ enhanced the strain resistance of hybrid system. Temperature was not demonstrated to have effects on the strain resistance of the hybrid system.

In frequency sweep test, the addition of $\mathrm{XG}$ significantly changed the frequency dependence, especially the trend of $G^{\prime}$. The $G^{\prime}$ value of pure SPI solution showed a negative correlation with frequency. However, after the addition of $\mathrm{XG}$, the correlation between $G^{\prime}$ and frequency became positive. As to the viscosity characteristic, the trend of $G^{\prime \prime}$ as a function of frequency flattened out with the addition of XG. It was demonstrated that the concentration of $\mathrm{XG}$ influenced the viscoelastic frequency dependence of the hybrid system significantly and complicatedly. Temperature acted a much ordinary role on affecting the frequency dependence properties of hybrid system. The value of $G^{\prime}$ and $G^{\prime \prime}$ both showed that less frequency dependency was changed with temperature rising. That meant the sensitivity on frequency of both elastic and viscous characteristic of hybrid system had a negative correlation with temperature.

\section{Acknowledgements}

This research was supported by Beijing Municipal Natural Science Foundation (6184036), Beijing Excellent Talent Training Project (2017000020124 G100), and Research Foundation for Youth Scholars of Beijing Technology and Business University (QNJJ2016-17).

\section{[References]}

[1] Di Masi A, Leboffe L, de Marinis E, Pagano F, Cicconi L, Rochette-Egly C, et al. Retinoic acid receptors: From molecular mechanisms to cancer therapy. Molecular Aspects of Medicine, 2015; 41: 1-115.

[2] Huysveld S, de Meester S, Peiren N, Muylle H, Lauwers L, Dewulf J. Resource use assessment of an agricultural system from a life cycle perspective-A dairy farm as case study. Agricultural Systems, 2015; 135: 77-89.

[3] Dekkers B L, Nikiforidis C V, van der Goot A J. Shear-induced fibrous structure formation from a pectin/SPI blend. Innovative Food Science \& Emerging Technologies, 2016; 36: 193-200.

[4] Liang H-N, Tang C-H. PH-dependent emulsifying properties of pea [Pisum sativum (L.)] proteins. Food Hydrocolloids, 2013; 33(2): 309-319.

[5] Muik B, Lendl B, Molina-Diaz A, Valcarcel M, Ayora-Cañada M J. Two-dimensional correlation spectroscopy and multivariate curve resolution for the study of lipid oxidation in edible oils monitored by FTIR and FT-Raman spectroscopy. Analytica Chimica Acta, 2007; 593(1): 54-67.

[6] Maltais A, Remondetto G E, Gonzalez R, Subirade M. Formation of soy protein isolate cold - set gels: Protein and salt effects. Journal of Food Science, 2005; 70(1).

[7] Bi C H, Li D, Wang L J, Adhikari B. Effect of LBG on the gel properties of acid-induced SPI gels. LWT-Food Science and Technology, 2017; pp.75: 1-8.

[8] Bi C H, Li D, Wang L J, Wang Y, Adhikari B. Characterization of non-linear rheological behavior of SPI-FG dispersions using LAOS tests and FT rheology. Carbohydrate polymers, 2013; 92(2): 1151-1158.

[9] Hazirah M N, Isa M, Sarbon N. Effect of xanthan gum on the physical and mechanical properties of gelatin-carboxymethyl cellulose film blends. Food Packaging and Shelf Life, 2016; 9: 55-63.

[10] Niknezhad S V, Asadollahi M A, Zamani A, Biria D. Production of xanthan gum by free and immobilized cells of Xanthomonas campestris 
and Xanthomonas pelargonii. International Journal of Biological Macromolecules, 2016; 82: 751-756.

[11] Kumar R S, Arthanareeswaran G, Paul D, Kweon J H. Effective removal of humic acid using xanthan gum incorporated polyethersulfone membranes. Ecotoxicology and Environmental Safety, 2015; 121: 223-228.

[12] Palaniraj A, Jayaraman V. Production, recovery and applications of xanthan gum by Xanthomonas campestris. Journal of Food Engineering, 2011; 106(1): 1-12.

[13] Krstonošić V, Dokić L, Nikolić I, Milanović M. Influence of xanthan gum on oil-in-water emulsion characteristics stabilized by OSA starch. Food Hydrocolloids, 2015; 45: 9-17.

[14] Zhao D, Liu H, Guo W, Qu L, Li C. Effect of inorganic cations on the rheological properties of polyacrylamide/xanthan gum solution. Journal of Natural Gas Science and Engineering, 2016; 31: 283-292.

[15] Khouryieh H, Puli G, Williams K, Aramouni F. Effects of xanthan-locust bean gum mixtures on the physicochemical properties and oxidative stability of whey protein stabilised oil-in-water emulsions. Food Chemistry, 2015; 167: 340-348.

[16] Chityala P K, Khouryieh H, Williams K, Conte E. Effect of xanthan/enzyme-modified guar gum mixtures on the stability of whey protein isolate stabilized fish oil-in-water emulsions. Food Chemistry, 2016; 212: 332-40

[17] Hayati I N, Ching C W, Rozaini M Z H. Flow properties of o/w emulsions as affected by xanthan gum, guar gum and carboxymethyl cellulose interactions studied by a mixture regression modelling. Food Hydrocolloids, 2016; 53: 199-208.

[18] Maury C, Sarni-Manchado P, Poinsaut P, Cheynier V, Moutounet M. Influence of polysaccharides and glycerol on proanthocyanidin precipitation by protein fining agents. Food Hydrocolloids, 2016; 60: 598-605.

[19] Liu J, Willför S, Xu C. A review of bioactive plant polysaccharides: Biological activities, functionalization, and biomedical applications. Bioactive Carbohydrates and Dietary Fibre, 2015; 5(1): 31-61.

[20] Bi C H, Li D, Wang L J, Gao F, Adhikari B. Effect of high shear homogenization on rheology, microstructure and fractal dimension of acid-induced SPI gels. Journal of Food Engineering, 2014; 126: 48-55.

[21] Cutter C N. Opportunities for bio-based packaging technologies to improve the quality and safety of fresh and further processed muscle foods. Meat Science, 2006; 74(1): 131-42.

[22] Sioutopoulos D, Goudoulas T, Kastrinakis E, Nychas S, Karabelas A. Rheological and permeability characteristics of alginate fouling layers developing on reverse osmosis membranes during desalination. Journal of Membrane Science, 2013; 434: 74-84.

[23] Mondal M I H, Yeasmin M S, Rahman M S. Preparation of food grade carboxymethyl cellulose from corn husk agrowaste. International Journal of Biological Macromolecules, 2015; 79: 144-150.

[24] Özkan N, Xin H, Chen X. Application of a depth sensing indentation hardness test to evaluate the mechanical properties of food materials. Journal of Food Science, 2002; 67(5): 1814-1820.

[25] Wei Y, Lin Y, Xie R, Xu Y, Yao J, Zhang J. The flow behavior, thixotropy and dynamical viscoelasticity of fenugreek gum. Journal of Food Engineering, 2015; 166: 21-28.

[26] Papagiannopoulos A, Sotiropoulos K, Pispas S. Particle tracking microrheology of the power-law viscoelasticity of xanthan solutions. Food Hydrocolloids, 2016; 61: 201-210.

[27] Drummond $\mathrm{C}$, In $\mathrm{M}$, Richetti P. Behavior of adhesive boundary lubricated surfaces under shear: Effect of grafted diblock copolymers. The European Physical Journal E: Soft Matter and Biological Physics, 2004; 15(2): 159-165.

[28] Bi C H, Li L T, Zhu Y D, Wu M, Li G, Huang Z G. Effect of high speed shear on the non-linear rheological properties of SPI/ $\kappa$-carrageenan hybrid dispersion and fractal analysis. Journal of Food Engineering, 2018; 218 : 80-87.

[29] Filali A, Khezzar L, Siginer D, Nemouchi Z. Graetz problem with non-linear viscoelastic fluids in non-circular tubes. International Journal of Thermal Sciences, 2012; 61: 50-60.

[30] Bi C H, Li D, Wang L J, Adhikari B. Viscoelastic properties and fractal analysis of acid-induced SPI gels at different ionic strength. Carbohydrate Polymers, 2013; 92(1): 98-105. 